\title{
Sepsis-Induced Cardiomyopathy: a Comprehensive Review
}

\section{Michael L'Heureux ${ }^{1} \cdot$ Michael Sternberg $^{2} \cdot$ Lisa Brath $^{1} \cdot$ Jeremy Turlington ${ }^{3} \cdot$ Markos G. Kashiouris $^{1}$}

Published online: 6 May 2020

(C) Springer Science+Business Media, LLC, part of Springer Nature 2020

\begin{abstract}
While sepsis-induced cardiomyopathy (SICM) has been recognized as a distinct entity since 1984, there are still no commonly agreed upon diagnostic criteria. This highlights a consequential gap in our collective medical knowledge with the potential to change patient outcomes.

Purpose of Review To briefly review epidemiology and pathophysiology of SICM and provide a more extensive review of the data on diagnostic and management strategies.

Recent Findings SICM is likely underdiagnosed and that has mortality implications. Current evidence supports speckle tracking echocardiography to identify decreased contractility irrespective of left ventricular ejection fraction for the diagnosis of SICM. There continues to be a dearth of large clinical trials evaluating the treatment of SICM and current consensus focuses on supportive measures such as vasopressors and inotropes.

Summary Sepsis is a significant cause of mortality, and sepsis-induced cardiomyopathy has both prognostic and management implications for these patients. Individualized work-up and management of these patients is crucial to improving outcomes.
\end{abstract}

Keywords Septic cardiomyopathy - Sepsis-induced cardiomyopathy - Sepsis-induced myocardial dysfunction · Sepsis . Echocardiography $\cdot$ Inotrope

\section{Introduction}

Sepsis is "a life-threatening condition that arises when the body's response to infection injures its own tissues" [1]. Despite significant advances in an organized treatment approach to sepsis, it remains the most common cause of death in critically ill patients worldwide [2] and the most frequent non-cardiac diagnosis in the cardiac intensive care unit [3]. Sepsis-induced cardiomyopathy (SICM), or sepsis-induced myocardial dysfunction (SIMD), is an increasingly recognized form of transient cardiac dysfunction in the septic

This article is part of the Topical Collection on Myocardial Disease

Michael L'Heureux

michael.lheureux@vcuhealth.org

Michael Sternberg

michael.sternberg@vcuhealth.org

Lisa Brath

lisa.brath@vcuhealth.org

Jeremy Turlington

jeremy.turlington@vcuhealth.org patients. Despite implications for patient outcomes, the critical care community has not given significant emphasis on this syndrome and prominent critical care textbooks $[4,5]$ do not have dedicated sections on SICM.

While no formal definitions exist for septic cardiomyopathy, most review articles and expert opinions agree on a few fundamental features of this unique form of cardiac dysfunction which are outlined in Fig. 1. One flaw to note is that in order to meet the criteria of reversibility, the patient must survive the episode. Given the high mortality with sepsis, this leads to bias which may affect both diagnosis and trials in SICM. 
Proposed Diagnostic Criteria for Sepsis-Induced Cardiomyopathy

Acute and reversible, within 7-10 days

Global, biventricular dysfunction (systolic and/or diastolic) with reduced contractility

Left ventricular dilation

Diminished response to fluid resuscitation and catecholamines

Absence of acute coronary syndrome as etiology

Fig. 1 Proposed diagnostic criteria for sepsis-induced cardiomyopathy

In this review, we will briefly summarize the epidemiology, pathophysiology, and clinical manifestations of SICM and then focus on diagnostic work-up and management in more detail.

\section{Epidemiology}

Sepsis-induced cardiomyopathy is encountered in the intensive care unit (ICU), and its prevalence in septic patients ranges from 10 to $70 \%$ [6]. This variety between studies is likely due to a lack of formal diagnostic criteria and under recognition. Moreover, the epidemiologic variance emphasizes the complex factors in sepsis: source and severity, promptness of resuscitation, and different antimicrobial and hemodynamic treatment approaches.

\section{Risk Factors}

A retrospective study of over 200 patients hospitalized with sepsis or septic shock demonstrated a higher prevalence of SICM in patients who were younger, male, those with higher illness severity scores, higher lactate and CRP levels, and pre-existing heart failure [7]. A more recent Korean study evaluated baseline risk factors for the development of SICM and stress-induced cardiomyopathy compared with controls. Increasing age, diabetes mellitus, pre-existing heart failure, and elevated proBNP were all associated with increased odds ratio for septic cardiomyopathy [8]. Again, there is some discrepancy between these studies that may be based on patient population (Japanese vs Korean, respectively), but both cite preexisting heart failure as a risk factor. It should also be noted that in both studies, SICM was defined as an "EF [ejection fraction] $<50 \%$ and $a \geq 10 \%$ decrease in the patient's baseline LVEF" [8]. It is possible that patients with RV failure, diastolic dysfunction, and abnormal cardiac strain were missed as will be outlined more later on.

\section{Prognosis}

Interestingly, the initial studies of SICM in the 1980s reported a "paradoxical" lower mortality in patients with lower initial Left Ventricular EF (LVEF) less than $40 \%$ and lower cardiac index (CI) [9]. While recent echocardiographic outcome prediction studies support these findings of $\operatorname{LVEF}[10,11 \bullet, 12]$, the strain of the myocardium (measured by echocardiographic speckle) was found to be a significant predictor of higher mortality in SICM [12•]. Additionally, isolated RV dysfunction in sepsis was associated with worse 1-year survival [13]. A recent database study suggested that among patients with sepsis, echocardiographic assessment of the myocardium influenced hemodynamic management liberated patients from vasopressors earlier and decreased 28-day mortality [14•]. In summary, LVEF is a poor diagnostic tool, and better measures, such as strain, do suggest that SICM portends a poorer prognosis and proper diagnosis will effect management to improve mortality.

\section{Pathogenesis and Pathophysiology}

A key early trial showed that infusion of LPS in human volunteers resulted in significant myocardial depression and left ventricular dilation within $5 \mathrm{~h}$ [15]. While it was initially thought that SICM was pathologically akin to coronary artery disease, a landmark study showed that the gross coronary perfusion is actually increased in patients with established septic shock [16]. Since these trials, many myocardial depressant factors have been identified including cytokines, components of the complement cascade, pathogen-associated molecular patterns, endogenous damage-associated molecular patterns, oxidative stress, altered nitric oxide metabolism, mitochondrial dysfunction, abnormal calcium movement within cells, myocyte apoptosis, and autonomic dysregulation [17, 18•]. Furthermore, the endothelial glycocalyx [19] is shed in sepsis causing vascular leak, coagulation, and inflammation and is associated with adverse outcomes [20]. Once disrupted, the endothelium can cause heterogeneous microvascular flow and myocardial edema [21] which is an underexplored mechanism of SICM. A very recent study [21] used cardiac magnetic resonance imaging and histology to show that myocardial edema may in part explain the rise of cardiac troponin seen in SICM. 


\section{Diagnosis}

Given that there is no definitive agreed upon definition or criteria, the diagnosis of SICM can be difficult. Moreover, it can be challenging to distinguish between cardiovascular system failure (i.e., distributive shock) and cardiac failure (i.e., SICM), and the two often coincide.

Clinical features that suggest the diagnosis include a prior history of heart failure, a "septic, cool extremities phenotype" on clinical exam, hemodynamic instability despite vasopressor therapy, failure to respond to a preload challenge, cardiac dysrhythmias, abnormal echocardiogram, low mixed venous oxygen saturation, and elevated cardiac troponins [9, 22, 23]. Herein we discuss diagnosis based on electrocardiogram, biomarkers, echocardiogram, and both invasive and non-invasive direct measures of cardiac output.

\section{Electrocardiogram}

There are no diagnostic electrocardiographic (ECG) findings of SICM. The most common rhythms include sinus tachycardia and atrial fibrillation (AF). A 2019 meta-analysis concluded that new onset atrial fibrillation occurs in patients without traditional risk factors for the development of AF suggestive that sepsis-induced cardiac changes lead to AF [24]. While the correlative relationship suggested by these studies links AF with SICM via a similar pathophysiology, it does not lend itself to using AF as a diagnostic or prognostic tool. It is also worth noting that approximately $2 \%$ of patients with fever have a fever-induced, type I Brugada pattern in the ECG, [25] a finding which may be confused with ST elevation due to myocardial ischemia. This is 20 times more common among febrile patients, compared with non-febrile patients [25]. While not diagnostic for SICM, any abnormal electrocardiograph, especially a change from the baseline, should prompt further cardiac evaluation.

\section{Biomarkers}

Troponin (cTn) In septic patients, elevated cTn is correlated with a greater degree of left ventricular dysfunction, illness severity, and mortality [26-29]. In a meta-analysis of over 1200 patients with sepsis, $61 \%$ of subjects with elevated cTn had a twofold increased risk of death compared with patients with undetectable cTn. Multivariate analysis confirmed that increased serum cTn was an independent risk factor for mortality [29]. Robust evidence linking cTn to prognosis and mortality has led some authors to recommend the use of cTn to risk stratify patients upon admission to the ICU $[29,30]$.

Brain Natriuretic Peptide (BNP) Natriuretic peptides also have prognostic value in sepsis $[11 \bullet, 31]$. A multicenter, randomized clinical trial of approximately 1000 patients with sepsis and septic shock showed that N-terminal pro-B-type BNP (NT-proBNP) and cTn were elevated in $97.4 \%$ and $84.5 \%$ of patients, respectively. The degree of biomarker elevation was highly correlated with the development of septic shock and mortality, but NT-proBNP predicted mortality in the ICU and at 90 days better than cTn [17]. Elevation of natriuretic peptides is so ubiquitous in sepsis that some investigators argue that any association with increased mortality is weakened when illness severity is considered [10].

Less studied molecules also implicated in septic-induced cardiac dysfunction include histones and heart fatty acidbinding proteins (hFABP). A study of 65 patients with sepsis in the ICU demonstrated that in patients without pre-existing cardiovascular disease, a high histone level showed a significant association with new-onset left ventricular dysfunction [32]. Another study of 93 patients with sepsis showed that patients with increased serum concentrations of hFABP had higher rates of cardiac dysfunction and were more likely to die within 28 days [33].

Overall, while elevated cardiac biomarkers are clear indicators of illness severity and prognosis in patients with sepsis, none of these biomarkers are specific to the diagnosis of SICM.

\section{Echocardiography}

Echocardiography is the cornerstone for the diagnosis of septic cardiomyopathy. There is consensus and expert opinion that every hemodynamically unstable patient should receive critical care echocardiography (CCE) $[34 \bullet, 35]$. These findings are summarized in Table 1 and described in more detail below.

LVEF It was initially thought that diagnosis could be made based solely by a depressed LVEF [9]. A major problem with the LVEF is that reduced afterload from the distributive shock may pseudo-normalize a depressed EF (coupling between contractility and afterload) [36, 37]. This likely leads to underdiagnosis of SICM when LVEF is used alone. We think that this explains the "paradox" of improved survival identified by Parker et al. [9] as a patient with profound shock (vasodilation) with a "normal EF" may do worse than one with less shock and a "low EF" $[36,37]$. Therefore, LVEF in critically ill patients should be reported with the amount of inotropic and vasopressor support and the degree of shock.

Stroke Volume (SV) and Cardiac Index (CI) Both SV and CI can be calculated using left ventricular outflow tract (LVOT) diameter and the velocity time integral (VTI), but the measurement of these indices is hard to interpret in SICM because of the profound variations in preload, afterload, and contractility intrinsic to septic shock. Studies have, however, found that 
Table 1 Echocardiographic findings in sepsis-induced cardiomyopathy

\begin{tabular}{|c|c|c|c|}
\hline Parameter & Modality & Strengths & Weaknesses \\
\hline LVEF & $\begin{array}{l}\text { Two-dimensional } \\
\text { echocardiography } \\
\text { - Semi-quantitative } \\
\text { (“eye-ball”) } \\
\text { - Quantitative }\end{array}$ & $\begin{array}{l}\text { Easy to obtain (including point of care) and } \\
\text { most clinicians are comfortable } \\
\text { interpreting the information }\end{array}$ & $\begin{array}{l}\text { Lacks sensitivity and specificity. May be } \\
\text { "pseudo-normalized" with low afterload. } \\
\text { Unclear prognostic role (low LVEF } \\
\text { "paradox") }\end{array}$ \\
\hline $\mathrm{SV}+\mathrm{CO}$ & Spectral Doppler & $\begin{array}{l}\text { Can be used to evaluate fluid responsiveness. } \\
\text { May be prognostic. Relatively easy to } \\
\text { obtain (point of care) }\end{array}$ & $\begin{array}{l}\text { Lacks sensitivity and specificity. Alterations } \\
\text { in preload, afterload, and contractility } \\
\text { will cause variations which can make } \\
\text { consistent interpretation difficult }\end{array}$ \\
\hline RV dysfunction & $\begin{array}{l}\text { Two-dimensional, spectral } \\
\text { Doppler, tissue Doppler }\end{array}$ & $\begin{array}{l}\text { Prognostic if present. TDI provides higher } \\
\text { quality information }\end{array}$ & $\begin{array}{l}\text { Lacks sensitivity and specificity. RV can be } \\
\text { difficult to visualize. More advanced } \\
\text { imaging techniques require formal } \\
\text { echocardiography }\end{array}$ \\
\hline Diastolic dysfunction & $\begin{array}{l}\text { Two-dimensional, spectral } \\
\text { Doppler, or tissue Doppler }\end{array}$ & $\begin{array}{l}\text { More prognostic than LVEF alone. Basic } \\
\text { information relatively easy to obtain, but } \\
\text { TDI provides higher quality information }\end{array}$ & $\begin{array}{l}\text { Lacks sensitivity and specificity. More } \\
\text { advanced imaging techniques require } \\
\text { formal echocardiography }\end{array}$ \\
\hline $\begin{array}{l}\text { Global longitudinal strain } \\
(\mathrm{LV}+\mathrm{RV})\end{array}$ & Speckle tracking & $\begin{array}{l}\text { Highly prognostic. Very sensitive assessment } \\
\text { of LV, RV, and diastolic dysfunction. Less } \\
\text { inter-observer variation. Not dependent on } \\
\text { physiology loading parameters }\end{array}$ & $\begin{array}{l}\text { Requires special software and equipment. } \\
\text { Requires high imaging quality (difficult } \\
\text { in critically-ill patients). Lack of } \\
\text { consensus on cut-off values }\end{array}$ \\
\hline
\end{tabular}

LVEF, left ventricle ejection fraction; SV, stroke volume; CO, cardiac output; RV, right ventricle; TDI, tissue Doppler imaging; LV, left ventricle

sepsis survivors have higher VTI and CI upon ED presentation [38].

Right Ventricle (RV) Systolic Dysfunction Approximately twothirds of patients with sepsis and septic shock have RV dysfunction and, as stated above, it is an independent risk factor of 1-year survival [13]. Measurements of RV function include the RV end-diastolic area in comparison to the $\mathrm{LV}$, the $\mathrm{RV}$ fractional area change with tricuspid annular plane systolic excursion and tricuspid annulus tissue Doppler imaging (TDI), and the RV free wall TDI have been used. A study suggested that the RV wall strain was the most important predictor of mortality in patient with SICM [11•]. All patients with a RV global longitudinal strain (GLS) less negative than $-13 \%$ died within 20 days [11•].

Diastolic Dysfunction LV diastolic function is very common in septic shock. The septal relaxation in TDI (e'-wave, abnormal $<8 \mathrm{~cm} / \mathrm{s}$ ) was a very strong predictor of mortality in septic shock patient, after adjusting for severity of illness, comorbidities, and other echocardiographic indices [39]. Another study measuring the peak early diastolic transmitral velocity during the passive filling of the heart (E)/peak early diastolic mitral annular TDI velocity (e') showed significant and independent prediction of mortality. The E/e' prime also allows approximation of the wedge pressure via the rough formula E/e' + 4.6 [40]. A recent meta-analysis confirmed these findings showing strong associations of both lower e' and higher E/e' in predicting mortality in critically ill patients with sepsis [41]. It is uncertain however, if specific reversible lusitropic interventions will improve outcomes [42].

Speckle Tracking Newer echocardiographic modalities have revealed further insight in SICM. Speckle tracking was developed in 2014 and uses advanced, non-Doppler algorithms to track myocardial segments, by the displacement of acoustic "speckles." A small pilot trial showed that myocardial impairment in sepsis can be detected by the global longitudinal strain (GLS), in other words, the displacement of myocardial speckles in the longitudinal axis, denoting the base-to-apex contractility of the heart. Normal values are -17 to $-23 \%$ (more negative is better). In patients with septic shock, GLS proved to be the most sensitive measurement of SICM with an average $-14 \%$ among patients with septic shock [43]. Interestingly the LVEF of those patients was normal [43]. A key benefit of the speckle tracking is that it is not as susceptible to afterload reduction pseudo-normalization that plagues the LVEF. Several trials have confirmed the benefit of the LV $[11 \bullet, 12 \bullet, 43-47]$, and the RV GLS [11•] in diagnosing SICM.

Gross Visual Examination In addition to "eyeballing" the LV and RV function and size, echocardiography allows evaluation of the large vessels and the pericardium. This is also important in ruling out other diagnoses in the differential of SICM such as sepsis-related Takotsubo cardiomyopathy, pericardial effusion, dissection, acute coronary syndromes, early dynamic intraventricular obstruction (IVO) syndromes such as systolic anterior motion of the mitral valve (SAM), and mid-cavitary obstruction syndromes [48]. 
Situational Awareness A final and key note for the echocardiographic evaluation of patients with possible septic cardiomyopathy is situational awareness. It is easy for a clinician to get distracted, lose track of time, and engage in prolonged echocardiographic evaluations of patients with suspected septic cardiomyopathy. This pitfall can divert the attention from lifesaving interventions such as ensuring timely and correct antimicrobial administration and securing the patient's airway. A recent study has shown that the point-of-care ultrasound and echocardiography were associated with delays and increased mortality in critically ill patients [49].

\section{Invasive Devices}

While it can be used to directly measure $\mathrm{CO}$ and other hemodynamic parameters, the pulmonary artery (PA) catheter has fallen out of favor because its use does not provide a mortality benefit [50]. In addition, a "normal" CO does not rule out SICM since a low SVR may falsely elevate the measured $\mathrm{CO}$, and $\mathrm{CO}$ does not necessarily reflect intrinsic cardiomyocyte function/contractility. To overcome the former barrier, Werdan et al. developed an "afterload-related cardiac performance" (ACP) calculation to integrate information from both SVR and CO [51]. The derived calculation is ACP $(\%)=\mathrm{CO}$ measured $/ C O$ predicted $\times 100 \%$ with $>80 \%$ considered normal. $\mathrm{CO}$ predicted was derived for this calculation with a nonlinear regression model obtained from a cohort of 524 patients. They reported that this measure has both diagnostic and prognostic utility in their small, single-center study [51]. In 2013, they expanded upon these findings with a larger study; however, all data was collected at the same center, and further studies are needed before many clinicians would consider resurrecting the routine use of PA catheters for this purpose [52].

\section{Non-Invasive Devices}

Non-invasive measures (such as pulse contour analysis, pulse pressure variation, and stroke volume variation) have an evidence-based role in evaluating fluid responsiveness in patients with septic shock, but there are certainly limitations to their use. We could not find any articles validating their use in the diagnosis or management of SICM. While they are promising devices, further studies are needed to validate their use in the setting of SICM prior to standardized use.

\section{Management}

There are no studies outlining treatment goals for SICM other than Dr. Rivers' initial study on early goal-directed therapy (EGDT) which is now the subject of debate [53]. Although the recent ProCESS, ARISE, and ProMISe studies showed no outcome differences when EGDT is applied indiscriminately, it is possible that a subset of patients with a diagnosis of SICM may benefit from titrating therapy to mixed venous oxygen saturation and lactate clearance, and future studies would be helpful [54-56]. As summary of current treatment, options are provided in Table 2.

\section{Vasopressors}

Based on previous studies, the surviving sepsis campaign recommends norepinephrine be used as first line for septic shock with epinephrine or vasopressin added as a second agent [63]. Norepinephrine has stronger alphaadrenergic profile compared with beta- 1 which results in increased afterload more than increased myocardial function. While this is essential for the treatment of distributive shock, increasing afterload will drop cardiac output and could result in the "unmasking" of cardiac dysfunction. While epinephrine and dopamine have more favorable alpha to beta- 1 adrenergic activity profiles, they are consequently associated with more arrhythmias. In the case of dopamine, risk of arrhythmias and potential increased mortality has led to the recommendation against its use for septic shock. It is worth noting that these guidelines did not identify patients with SICM and are guides for the management of septic shock in general. There are no trials that we could find to validate adopting these guidelines to patients with SICM [57]. There was one study which showed that phenylephrine improved cardiac function in septic rats and inhibited myocyte apoptosis suggesting that this could be used specifically for SICM, but there are no corresponding human studies [58]. The risk of isolated alpha-vasoconstriction without any beta- 1 could cause increased afterload and decreased $\mathrm{CO}$ potentially worsening hemodynamics so further studies are needed.

\section{Fluid Management}

It is being increasingly recognized that over resuscitation can have detrimental effects. Studies, such as the SOAP trial, show that a positive fluid balance is a poor prognostic factor [59]. This effect is likely to be more dramatic in patients with septic cardiomyopathy because of abnormal Frank-Starling relationships. It is necessary to be judicious with fluid management after the initial resuscitation phase by using dynamic measures of fluid responsiveness such as pulse pressure variation, inferior vena cava collapse, passive straight leg raise, and end-expiratory occlusion. While each of these measures has strengths and weakness, the overarching goal of these measures is to account for differences in cardiac function as it relates to fluid responsiveness in a dynamic manner rather than traditional static 
Table 2 Management of sepsis-induced cardiomyopathy

\begin{tabular}{|c|c|c|c|}
\hline Therapy & Mechanism of action & Pro & Con \\
\hline Vasopressors & $\begin{array}{l}\text { Vasoconstriction by alpha or beta } \\
\text { adrenergic, vasopressin, or } \\
\text { dopamine receptor stimulation }\end{array}$ & $\begin{array}{l}\text { Physician familiarity. Well studied in septic } \\
\text { shock. Alpha-adrenergic, dopamine, and } \\
\text { vasopressin activity will help with decreased } \\
\text { afterload. Beta and dopamine activity will } \\
\text { increase contractility }\end{array}$ & $\begin{array}{l}\text { Increasing afterload too much may "unmask" } \\
\text { cardiac dysfunction (especially with isolated } \\
\text { vasoconstrictive drugs phenylephrine and } \\
\text { vasopressin). The beta-adrenergic and } \\
\text { dopamine activity could increase myocardial } \\
\text { demand leading to worsening cardiomyopathy } \\
\text { and/or arrhythmias }\end{array}$ \\
\hline Fluids & $\begin{array}{l}\text { Increasing preload with increase } \\
\text { stroke volume based on } \\
\text { Frank-Starling relationships }\end{array}$ & $\begin{array}{l}\text { Increasing stroke volume will increase cardiac } \\
\text { output }\end{array}$ & $\begin{array}{l}\text { Cardiomyopathy will shift the Frank-Starling } \\
\text { curve and overaggressive fluid management } \\
\text { can lead to worsening organ failure }\end{array}$ \\
\hline Dobutamine & Beta-adrenergic selective agent & $\begin{array}{l}\text { Physician familiarity. Most studied with proven } \\
\text { improvement in cardiac parameters (i.e., CO) }\end{array}$ & $\begin{array}{l}\text { Increased myocardial demand and vasodilation } \\
\text { may worsen hemodynamics. Risk of } \\
\text { arrhythmias. May not improve outcomes }\end{array}$ \\
\hline Milrinone & $\begin{array}{l}\text { Phosphodiesterase inhibitor } \\
\text { increases cAMP }\end{array}$ & $\begin{array}{l}\text { Increased contractility without adrenergic } \\
\text { activity. No trials for SICM }\end{array}$ & $\begin{array}{l}\text { Vasodilation. Limited by renal dysfunction. Risk } \\
\text { of arrhythmias }\end{array}$ \\
\hline Levosimendan & $\begin{array}{l}\text { Calcium sensitizer and } \\
\text { potassium channel activator }\end{array}$ & $\begin{array}{l}\text { Helps with calcium signaling to increase } \\
\text { contractility in an adrenergic-dependent } \\
\text { manner so less oxygen demand }\end{array}$ & $\begin{array}{l}\text { Vasodilation. Mixed information about mortality } \\
\text { with the largest trial suggesting increased } \\
\text { mortality }\end{array}$ \\
\hline Beta blockers & Beta-adrenergic blockade & $\begin{array}{l}\text { May help decrease the pathogenesis of SICM by } \\
\text { decrease myocardial demand }\end{array}$ & $\begin{array}{l}\text { Negative inotropic effect. Patients with cardiac } \\
\text { dysfunction were excluded from the largest } \\
\text { trials }\end{array}$ \\
\hline Ivabradine & $\begin{array}{l}\text { Selective inhibitor of the } \mathrm{I}_{\mathrm{f}} \\
\text { channel }\end{array}$ & $\begin{array}{l}\text { Lower myocardial demand without negative } \\
\text { inotropic effect found in beta blockers }\end{array}$ & $\begin{array}{l}\text { Possible worsened mortality, but data sparse and } \\
\text { not specific to SICM }\end{array}$ \\
\hline $\begin{array}{l}\text { Methylene } \\
\text { blue }\end{array}$ & Nitric oxide metabolism & $\begin{array}{l}\text { Treats vasoplegia. Improves catecholamine } \\
\text { responsiveness. May improve vasopressor } \\
\text { requirement }\end{array}$ & $\begin{array}{l}\text { No change in outcomes. Risk of serotonin } \\
\text { syndrome. Can cause worsening oxygenation } \\
\text { by pulmonary vasoconstriction. Hemolytic } \\
\text { anemia in G6PD deficiency. Interference with } \\
\text { pulse oximetry. Contraindicated with renal } \\
\text { dysfunction }\end{array}$ \\
\hline $\begin{array}{l}\text { Mechanical } \\
\text { support }\end{array}$ & $\begin{array}{l}\text { Provide bypass or mechanical } \\
\text { assistance of cardiac output }\end{array}$ & $\begin{array}{l}\text { Provides aggressive supportive care until } \\
\text { reversibility occurs }\end{array}$ & $\begin{array}{l}\text { Invasive with relatively high risk of } \\
\text { complications. Must choose right device }\end{array}$ \\
\hline
\end{tabular}

CO, cardiac output; cAMP, cyclic adenosine monophosphate; SICM, sepsis-induced cardiomyopathy; G6PD, glucose-6-phosphate dehydrogenase

measures (i.e., CVP, PCWP). Currently the PETAL Network is recruiting for the Crystalloid Liberal or Vasopressors Early Resuscitation in Sepsis (CLOVERS) to further evaluate this topic. Patients with known contraindications to liberal fluids are excluded from the trial and this may make generalizability to patients with SICM difficult.

\section{Inotropes}

The Surviving Sepsis Guidelines currently support the use of dobutamine to augment vasopressor therapy in the appropriate clinical scenarios, but the evidence for its use is sparse. There certainly are potential downfalls to the use of inotropic agents in septic cardiomyopathy, such as increase myocardial demand and vasodilation. Because of their mechanism of actions, milrinone and levosimendan have the theoretical advantage of acting outside of the adrenergic pathway which is known to be dysfunction in SICM.
Dobutamine A meta-regression analysis by Naedeem et al. did showed improved cardiovascular parameters in patients with septic shock treated with dobutamine which justifies the efficacy of dobutamine but did not investigate outcomes [60]. Hernandez and colleagues, however, performed a randomized controlled trial on the microcirculatory perfusion in patients with septic shock with low cardiac output, and despite an increase in $\mathrm{CI}$, those parameters did not improve with dobutamine [61]. This suggests that although CO improves with dobutamine, it may not overcome the end-organ damage intrinsic in septic states. It seems intuitive that cardiac output needs to be supraphysiologic in the septic state, but Gattinoni et al. found that targeting supranormal values of cardiac index did not improve morbidity or mortality $[62,63]$.

Given the potential pitfalls of inotropic therapy, there are some studies to corroborate the downsides. Hayes et al. found that using dobutamine to augment cardiac index and systemic oxygen delivery worsened in-hospital mortality. In this study, though, all patients were treated with dopamine, and we can surmise from the dopamine data that the combination of 
dopamine and dobutamine is high risk for arrhythmias [64]. Further, a retrospective study by Wilkman et al. showed an increased 90-day mortality in patients with septic shock treated with inotropes [65]. Only a correlation, however, can be surmised from that study which may be representative of worse prognosis with septic cardiomyopathy. This seems to be supported by trials by Rhodes and Kumar in which they showed failure of cardiac output to increase with dobutamine portends a poorer prognosis [66, 67]. Two other interesting studies on potential pitfalls of dobutamine are done by Lyte suggesting that dobutamine facilitates biofilm formation on indwelling catheters in vitro and one by Hartemink in which dobutamine is associated with increased circulating TNFalpha levels $[68,69]$.

Milrinone There are even fewer studies on the use of milrinone in sepsis and none in septic cardiomyopathy. In a pediatric trial, Barton showed improved cardiovascular function with milrinone in patients with "nonhyperdynamic" septic shock without adverse outcomes (did not include patients with $\mathrm{Cr}$ $>2.0$ ) [70]. A prospective, non-randomized trial in septic shock found that the combination of milrinone and PO metoprolol augmented cardiac index with lower heart rate and higher stroke volume index potentially mitigating the arrhythmogenic side effects of inotropes [71]. One major factor to consider is renal impairment which is present in many patients with sepsis and may limit widespread use.

Levosimendan Levosimendan is an attractive therapy for septic cardiomyopathy because it targets cardiomyocyte calcium signaling which is known to be pathologic in septic cardiomyopathy. Moreover, it acts in a catecholamine-independent manner to minimize effects on oxygen demand, arrhythmias, and catecholamine resistance from sepsis. Morelli et al. performed a randomized, prospective trial published in 2005 which showed levosimendan improved hemodynamics $(\mathrm{LVEF}+\mathrm{CI})$ in patients not responsive to dobutamine at $5 \mathrm{microg} / \mathrm{kg} / \mathrm{min}$ because of adrenergic hyporesponsiveness. They also showed that levosimendan increased gastric mucosal flow, creatinine clearance, urine output, and lactate clearance compared with dobutamine [72]. A meta-analysis (of 7 trials) by Zangrillo published in 2015 showed that levosimendan had a mortality benefit when compared to dobutamine [73]. The next major trial to come out was the LeoPARDS trial in 2016. This double-blind RCT compared levosimendan to placebo plus standard of care for sepsis and found no difference in SOFA scores or mortality but a trend toward worse mortality with levosimendan. In addition, the levosimendan group was more likely to have SVT, required higher vasopressor doses, and was less likely to be weaned from ventilator. Of note, in the placebo arm, less than $10 \%$ of patients received inotropic support, which does bring into question the prevalence of SICM in the study population
[74•]. Overall, the data for levosimendan is mixed, and the LeoPARDS trial should give practitioners pause before adopting its use broadly.

\section{Rate Control}

Beta Blockers Beta blockers have been shown to be beneficial in many cardiovascular diseases, but their use in sepsis is controversial. It would seem that any negative inotropic effects would be detrimental to a patient who is relying on a hyperdynamic state, but this increased adrenergic state seems to play a role in the pathogenesis of septic cardiomyopathy. For this reason, the use of selective beta-blockers may help to decrease myocardial oxygen demand, increase diastolic filling, and ultimately improve septic cardiomyopathy. Early studies showed that esmolol did not change lactate and reduced TNF-alpha levels, and that beta- 1 selective agents may have anti-inflammatory effects $[75,76]$. An observational study of 9465 cases of sepsis found that patients prescribed with beta-blockers prior to admission had a significantly lower mortality (17.7\% vs $22.1 \%)$ [77]. This sparked interest in prospective studies, the largest of which was performed by Morelli; they performed a non-blinded RCT which showed that the use of esmolol targeting a heart rate of 80-94 increased stroke volume and reduced vasopressor requirement. They also found an improved 28-day survival, but they were not powered for this outcome, and mortality in the placebo group was $80 \%$ which is much higher than expected [78•]. Moreover, patients with cardiac dysfunction were excluded from this trial, so its application to patients with SICM is unknown.

Ivabradine Ivabradine is an attractive rate control agent because it provides heart rate lowering effects without the negative inotropy associated with beta blockers. An observational study of 3 patients found that its use improved heart rate, stroke volume index, end-diastolic volume index, and $\mathrm{SvO} 2$ while decreasing lactate and norepinephrine dose [79]. This should be taken with a grain of salt as a larger trial demonstrated a trend toward worsened mortality in ivabradine group, but this did not reach statistical significance [80•]. This larger trial, however, is difficult to interpret in relation to SICM as patients with both cardiac and septic shock were included, and the subgroups were not analyzed separately.

\section{Methylene Blue (MB)}

As noted earlier, nitric oxide metabolism plays a role in the development of septic shock when inflammatory substrate activates nitric oxide synthase (NOS) thus increasing NO production. This has a vasodilatory effect as well as 
impairing the cardiovascular systems response to catecholamines. Methylene blue has routinely been used to treat vasoplegia after cardiovascular surgery because it acts by inhibiting guanylate cyclase and NOS to counteract this mechanism. A 2014 review by Lo et al. found 16 articles on the topic of MB for the treatment of septic shock including two randomized controlled studies. These studies showed a significant improvement in blood pressure and decreased requirement for vasopressors but no difference in other outcomes [81-83]. There is only one case report

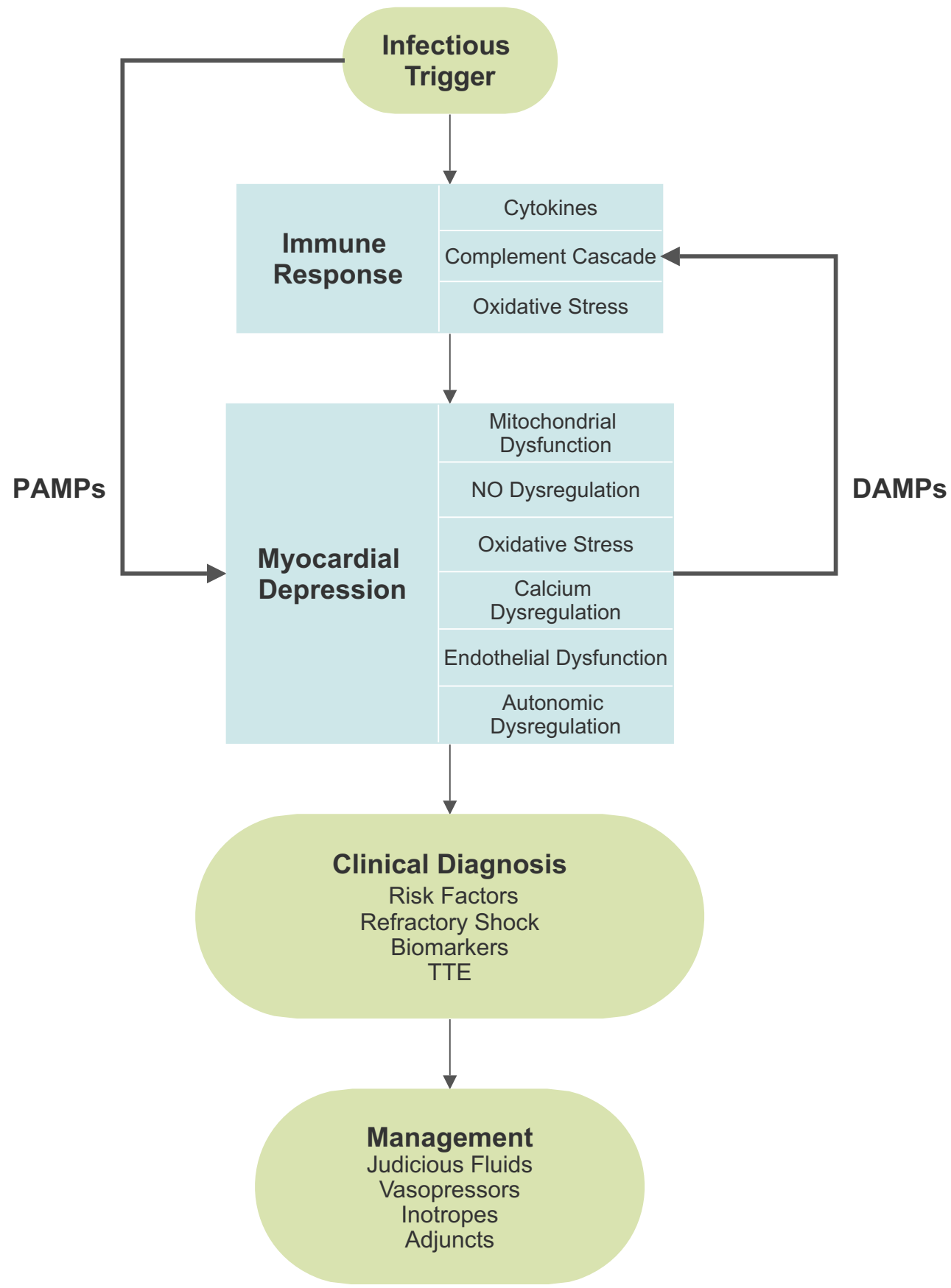

Fig. 2 Summary of basic pathophysiology and proposed diagnosis and management of sepsis-induced cardiomyopathy. Risk factors include a history of congestive heart failure. Biomarkers while sensitive, are not specific, but do portent a poorer prognosis. Echocardiography should include global longitudinal strain which is the most sensitive and specific (although there are no agreed upon cutoff values). Judicious fluids should include dynamic measures (such as pulse pressure variation) to judge fluid responsiveness. Norepinephrine is considered the standard vasopressor and dobutamine is considered the standard inotrope. There is limited evidence for other vasopressors or inotropes. Adjuncts can include mechanical support (i.e. ECMO). PAMPs, pathogen-associated molecular patterns; DAMPs, damage-associated molecular patterns; NO, nitric oxide; TTE, transthoracic echocardiogram; ECMO, extracorporeal membrane oxygenation 
describing the successful use of MB specifically for septic cardiomyopathy in a burn patient by Schlesinger in 2016 [84]. Like all therapies, MB is not without risks; it can contribute to serotonin syndrome, worsening arterial oxygenation (through pulmonary vasoconstriction), infiltration injury, and impaired mesenteric blood flow. Overall, MB is a potential treatment for septic shock, and more evidence is necessary before it can be adopted broadly for the treatment of septic cardiomyopathy.

\section{Mechanical Support}

Mechanical support is widely used in cardiogenic shock due to congestive heart failure, and its use in septic cardiomyopathy is based upon that experience. There are no randomized controlled trials for intra-aortic balloon pump (IABP), percutaneous ventricular assist devices, or extracorporeal membrane oxygenation (ECMO). There are multiple case reports providing examples of both successful and unsuccessful use of these devices in patients with septic cardiomyopathy. One consideration before deciding on the appropriate support device is the patient-specific hemodynamics such as LV, RV, or $\mathrm{Bi}-\mathrm{V}$ failure and systolic vs diastolic dysfunction. In their 2015 review, Sato and Nasu provide a summary of the ECMO case reports in which 18/23 patients survived [30]. Without larger studies, this therapy should only be considered in extreme cases.

\section{Emerging Therapies}

As our understanding of the pathophysiology of SICM grows, so does the potential for targeted therapy. There are many potential therapies being investigated in the laboratory setting, largely in animal models of septic cardiomyopathy. Potential therapies include statins, dexmedetomidine, hydrocortisone, alpha-2 blockers, yohimbine, Chinese yam, erythropoietin, vitamin c, and sulfur dioxide among others [85-96]. As these treatments transition from the bench to the bedside, potential therapeutic efficacy will need to be evaluated. It is important to remember from historical studies in sepsis in the 1990's that translation of animal models to human studies has its limitations [85].

\section{Conclusion}

SICM is currently an under recognized entity that has significant prognostic and mortality implications for our patients. A summary of the basic pathophysiology, work-up, and management of SICM is provided in Fig. 2. Clinicals should consider the diagnosis in patients with sepsis-associated organ dysfunction and particularly septic shock requiring vasopressor therapy. Biomarkers can provide prognostic information and put
SICM on the clinician's radar, but their diagnostic utility is limited. Echocardiography is currently the gold standard of diagnosis, and evaluation of global longitudinal strain is more sensitive and specific for SICM than LVEF or other common findings alone. Standard management includes the use of vasopressors, inotropes, and judicious fluid resuscitation, but large studies validating these measures are lacking. Additionally, while there is growing evidence for other therapies for SICM, more data is needed to make any definitive recommendations about adopting them to everyday practice. Finally, a consensus statement on diagnostic criteria is currently lacking and is essential in future studies evaluating treatment.

Acknowledgments The work has been performed at the Virginia Commonwealth University Medical Center.

\section{Compliance with Ethical Standards}

Conflict of Interest Michael L'Heureux, Michael Sternberg, Lisa Brath, Jeremy Turlington, and Markos G. Kashiouris report no research funding or conflicts of interest in this study.

Human and Animal Rights This article does not contain any studies with human or animal subjects performed by any of the authors.

\section{References}

Papers of particular interest, published recently, have been highlighted as:

- Of importance

1. Singer M, Deutschman CS, Seymour CW, Shankar-Hari M, Annane D, Bauer M, et al. The third international consensus definitions for sepsis and septic shock (Sepsis-3). JAMA. 2016;315: 801-10.

2. Vincent J-L, Marshall JC, Namendys-Silva SA, François B, MartinLoeches I, Lipman J, et al. Assessment of the worldwide burden of critical illness: the intensive care over nations (ICON) audit. Lancet Respir Med. 2014;2:380-6.

3. Holland EM, Moss TJ. Acute noncardiovascular illness in the cardiac intensive care unit. J Am Coll Cardiol. 2017;69:1999-2007.

4. Webb A, Angus D, Finfer S, Gattinoni L, Singer M. Oxford textbook of critical care. Oxford: Oxford University Press; 2016.

5. Schmidt GA, Wood LD, Hall JB, Ali J. Principles of critical care 4th edition. Principles of critical care 2015

6. Beesley SJ, Weber G, Sarge T, Nikravan S, Grissom CK, Lanspa MJ, et al. Septic cardiomyopathy. Crit Care Med. 2018;46:625-34.

7. Sato R, Kuriyama A, Takada T, Nasu M, Luthe SK. Prevalence and risk factors of sepsis-induced cardiomyopathy: a retrospective cohort study. Medicine. 2016;95:e5031.

8. Jeong HS, Lee TH, Bang CH, Kim J-H, Hong SJ. Risk factors and outcomes of sepsis-induced myocardial dysfunction and stressinduced cardiomyopathy in sepsis or septic shock: a comparative retrospective study. Medicine. 2018;97:e0263.

9. Parker MM, Shelhamer JH, Bacharach SL, Green MV, Natanson C, Frederick TM, et al. Profound but reversible myocardial depression in patients with septic shock. Ann Intern Med. 1984;100:483-90. 
10. Huang SJ, Nalos M, McLean AS. Is early ventricular dysfunction or dilatation associated with lower mortality rate in adult severe sepsis and septic shock? A meta-analysis. Crit Care. 2013;17:R96.

11. Orde SR, Pulido JN, Masaki M, Gillespie S, Spoon JN, Kane GC, et al. Outcome prediction in sepsis: speckle tracking echocardiography based assessment of myocardial function. Crit Care. 2014;18: R149. Important study on speckle tracking echocardiography.

12. Sanfilippo F, Corredor C, Fletcher N, Tritapepe L, Lorini FL, Arcadipane A, et al. Left ventricular systolic function evaluated by strain echocardiography and relationship with mortality in patients with severe sepsis or septic shock: a systematic review and meta-analysis. Crit Care. 2018;22:183. Systematic review on speckle tracking echocardiography.

13. Vallabhajosyula S, Kumar M, Pandompatam G, Sakhuja A, Kashyap R, Kashani K, et al. Prognostic impact of isolated right ventricular dysfunction in sepsis and septic shock: an 8-year historical cohort study. Ann Intensive Care. 2017;7:94.

14. Feng M, McSparron JI, Kien DT, Stone DJ, Roberts DH, Schwartzstein RM, et al. Transthoracic echocardiography and mortality in sepsis: analysis of the MIMIC-III database. Intensive Care Med. 2018;44:884-92. Echocardiography and mortality.

15. Parrillo JE, Parker MM, Natanson C, Suffredini AF, Danner RL, Cunnion RE, et al. Septic shock in humans. Advances in the understanding of pathogenesis, cardiovascular dysfunction, and therapy. Ann Intern Med. 1990;113:227-42.

16. Dhainaut JF, Huyghebaert MF, Monsallier JF, Lefevre G, Dall'AvaSantucci J, Brunet F, et al. Coronary hemodynamics and myocardial metabolism of lactate, free fatty acids, glucose, and ketones in patients with septic shock. Circulation. 1987;75:533-41.

17. Ehrman RR, Sullivan AN, Favot MJ, Sherwin RL, Reynolds CA, Abidov A, et al. Pathophysiology, echocardiographic evaluation, biomarker findings, and prognostic implications of septic cardiomyopathy: a review of the literature. Crit Care. 2018;22:112.

18. Lv X, Wang H. Pathophysiology of sepsis-induced myocardial dysfunction. Mil Med Res. 2016;3:30. More in depth look at pathophysiology.

19. Uchimido R, Schmidt EP, Shapiro NI. The glycocalyx: a novel diagnostic and therapeutic target in sepsis. Crit Care. 2019;23:16.

20. Smart L, Bosio E, Macdonald SPJ, Dull R, Fatovich DM, Neil C, et al. Glycocalyx biomarker syndecan-1 is a stronger predictor of respiratory failure in patients with sepsis due to pneumonia, compared to endocan. J Crit Care. 2018;47:93-8.

21. Vasques-Nóvoa F, Laundos TL, Madureira A, Bettencourt N, Nunes JPL, Carneiro F, et al. Myocardial edema: an overlooked mechanism of septic cardiomyopathy? Shock. 2019

22. Clowes GH, Vucinic M, Weidner MG. Circulatory and metabolic alterations associated with survival or death in peritonitis: clinical analysis of 25 cases. Ann Surg. 1966;163:866-85.

23. Waisbren BA. Bacteremia due to gram-negative bacilli other than the salmonella. AMA Arch Intern Med. 1951;88:467.

24. Bosch NA, Cohen DM, Walkey AJ. Risk factors for new-onset atrial fibrillation in patients with Sepsis: a systematic review and meta-analysis. Crit Care Med. 2019;47:280-7.

25. Adler A, Topaz G, Heller K, Zeltser D, Ohayon T, Rozovski U, et al. Fever-induced Brugada pattern: how common is it and what does it mean? Heart Rhythm. 2013;10:1375-82.

26. Martin L, Derwall M, Al Zoubi S, Zechendorf E, Reuter DA, Thiemermann C, et al. The septic heart: current understanding of molecular mechanisms and clinical implications. Chest. 2019;155: 427-37.

27. Romero-Bermejo FJ, Ruiz-Bailen M, Guerrero-De-Mier M, LopezAlvaro J. Echocardiographic hemodynamic monitoring in the critically ill patient. CCR. 2011;7:146-56.

28. Masson S, Caironi P, Fanizza C, Carrer S, Caricato A, Fassini P, et al. Sequential N-terminal pro-B-type natriuretic peptide and highsensitivity cardiac troponin measurements during albumin replacement in patients with severe sepsis or septic shock. Crit Care Med. 2015;44:707-16.

29. Bessière F, Khenifer S, Dubourg J, Durieu I, Lega J-C. Prognostic value of troponins in sepsis: a meta-analysis. Intensive Care Med. 2013;39:1181-9.

30. Sato R, Nasu M. A review of sepsis-induced cardiomyopathy. J Intensive Care. 2015;3:48.

31. Charpentier J, Luyt C-E, Fulla Y, Vinsonneau C, Cariou A, Grabar $\mathrm{S}$, et al. Brain natriuretic peptide: a marker of myocardial dysfunction and prognosis during severe sepsis. Crit Care Med. 2004;32: $660-5$.

32. Alhamdi Y, Abrams ST, Cheng Z, Jing S, Su D, Liu Z, et al. Circulating histones are major mediators of cardiac injury in patients with sepsis. Crit Care Med. 2015;43:2094-103.

33. Zhang Z, Dai H, Yu Y, Yang J, Hu C. Usefulness of heart-type fatty acid-binding protein in patients with severe sepsis. J Crit Care. 2012;27:415.e13-8

34. Vieillard-Baron A, Millington SJ, Sanfilippo F, Chew M, DiazGomez J, McLean A, et al. A decade of progress in critical care echocardiography: a narrative review. Intensive Care Med. 2019;45:770-88. Extensive review of critical care echocardiography.

35. Alhamid S, Balik M, Beaulieu Y, Breitkreutz R. Expert Round Table on Echocardiography in ICU. International consensus statement on training standards for advanced critical care echocardiography. Intensive Care Med. 2014;40:654-66.

36. Repessé X, Charron C, Vieillard-Baron A. Evaluation of left ventricular systolic function revisited in septic shock. Crit Care. 2013;17:164.

37. Robotham JL, Takata M, Berman M, Harasawa Y. Ejection fraction revisited. Anesthesiology. 1991;74:172-83.

38. Santos T, Schweller M, Gontijo-Coutinho C, Franci D, Nocera P, Guerra-Grangeia T, et al. Sepsis survivors present with higher values of cardiac index and velocity time integral in the emergency department. Crit Care. 2015;19:P137.

39. Landesberg G, Gilon D, Meroz Y, Georgieva M, Levin PD, Goodman S, et al. Diastolic dysfunction and mortality in severe sepsis and septic shock. Eur Heart J. 2012;33:895-903.

40. Garcia MJ, Ares MA, Asher C, Rodriguez L, Vandervoort P, Thomas JD. An index of early left ventricular filling that combined with pulsed Doppler peak E velocity may estimate capillary wedge pressure. J Am Coll Cardiol. 1997;29:448-54.

41. Sanfilippo F, Corredor C, Arcadipane A, Landesberg G, VieillardBaron A, Cecconi M, et al. Tissue Doppler assessment of diastolic function and relationship with mortality in critically ill septic patients: a systematic review and meta-analysis. $\mathrm{Br} \mathrm{J}$ Anaesth. 2017;119:583-94.

42. Herpain A, Bouchez S, Girardis M, Guarracino F, Knotzer J, Levy B, et al. Use of levosimendan in intensive care unit settings: an opinion paper. J Cardiovasc Pharmacol. 2019;73:3-14.

43. Ng PY, Sin WC, Ng AK-Y, Chan WM. Speckle tracking echocardiography in patients with septic shock: a case control study (SPECKSS). Crit Care. 2016;20:145.

44. Vallabhajosyula S, Rayes HA, Sakhuja A, Murad MH, Geske JB, Jentzer JC. Global longitudinal strain using speckle-tracking echocardiography as a mortality predictor in Sepsis: a systematic review. J Intensive Care Med. 2019;34:87-93.

45. Hoffman M, Kyriazis ID, Lucchese AM, de Lucia C, Piedepalumbo M, Bauer M, et al. Myocardial strain and cardiac output are preferable measurements for cardiac dysfunction and can predict mortality in septic mice. J Am Heart Assoc. 2019;8:e12260.

46. Ehrman RR, Moore SC, Favot MJ, Akers KG, Gallien JZ, Welch $\mathrm{RD}$, et al. Scientific letter to the editor: need for a definitive study of global longitudinal strain for prognostication in septic cardiomyopathy. J Am Soc Echocardiogr. 2019;32:549-552.e3. 
47. Corda A, Pinna Parpaglia ML, Sotgiu G, Zobba R, Gomez Ochoa P, Prieto Ramos J, et al. Use of 2-dimensional speckle-tracking echocardiography to assess left ventricular systolic function in dogs with systemic inflammatory response syndrome. J Vet Intern Med. 2019;33:423-31.

48. Chauvet J-L, El-Dash S, Delastre O, Bouffandeau B, Jusserand D, Michot J-B, et al. Early dynamic left intraventricular obstruction is associated with hypovolemia and high mortality in septic shock patients. Crit Care. 2015;19:262.

49. Mosier JM, Stolz U, Milligan R, Roy-Chaudhury A, Lutrick K, Hypes CD, et al. Impact of point-of-care ultrasound in the emergency department on care processes and outcomes in critically ill nontraumatic patients. Crit Care Explor. 2019;1.

50. Harvey S, Young D, Brampton W, Cooper AB, Doig G, Sibbald W, et al. Pulmonary artery catheters for adult patients in intensive care. Cochrane Database Syst Rev. 2006;CD003408.

51. Werdan K, Oelke A, Hettwer S, Nuding S, Bubel S, Hoke R, et al. Septic cardiomyopathy: hemodynamic quantification, occurrence, and prognostic implications. Clin Res Cardiol. 2011;100:661-8.

52. Wilhelm J, Hettwer S, Schuermann M, Bagger S. Severity of cardiac impairment in the early stage of community-acquired sepsis determines worse prognosis. Clin Res Cardiol. 2013;102(10):73544.

53. Rivers E, Nguyen B, Havstad S, Ressler J, Muzzin A, Knoblich B, et al. Early goal-directed therapy in the treatment of severe sepsis and septic shock. N Engl J Med. 2001;345:1368-77.

54. Angus DC, Yealy DM, Kellum JA. Protocol-based care for early septic shock. N Engl J Med. 2014;371(4):386-7.

55. ARISE Investigators and the ANZICS Clinical Trials Group. Goaldirected resuscitation for patients with early septic shock. N Engl J Med. 2014;371(16):1496-506.

56. Mouncey PR, Osborn TM, Power GS, Harrison DA, Sadique MZ, Grieve RD, et al. Trial of early, goal-directed resuscitation for septic shock. N Engl J Med. 2015;372:1301-11.

57. Rhodes A, Evans LE, Alhazzani W, Levy MM, Antonelli M, Ferrer $\mathrm{R}$, et al. Surviving sepsis campaign: international guidelines for management of sepsis and septic shock: 2016. Crit Care Med. 2017;45:486-552.

58. Li H, Xing Y, Yang D, Tang X, Lu D, Wang H. Alpha-1 adrenergic receptor agonist phenylephrine inhibits sepsis-induced cardiomyocyte apoptosis and cardiac dysfunction via activating ERK1/2 signal pathway. Shock. 2019;52(1):122-33.

59. Vincent J-L, Sakr Y, Sprung CL, Ranieri VM, Reinhart K, Gerlach $\mathrm{H}$, et al. Sepsis in European intensive care units: results of the SOAP study. Crit Care Med. 2006;34:344-53.

60. Nadeem R, Sockanathan S, Singh M. Impact of Dobutamine in Patients With Septic Shock: A Meta-Regression Analysis. Am J Ther. 2017;24(3):e333-46.

61. Hernandez G, Bruhn A, Luengo C, Regueira T, Kattan E, Fuentealba A, et al. Effects of dobutamine on systemic, regional and microcirculatory perfusion parameters in septic shock: a randomized, placebo-controlled, double-blind, crossover study. Intensive Care Med. 2013;39:1435-43.

62. Gattinoni L, Brazzi L, Pelosi P, Latini R, Tognoni G, Pesenti A, et al. A trial of goal-oriented hemodynamic therapy in critically ill patients. SvO2 collaborative group. N Engl J Med. 1995;333:102532.

63. Gattinoni L, Tognoni G, Pesenti A, Taccone P, Mascheroni D, Labarta V, et al. Effect of prone positioning on the survival of patients with acute respiratory failure. N Engl J Med. 2001;345: 568-73.

64. Hayes MA, Timmins AC, Yau EH, Palazzo M, Hinds CJ, Watson D. Elevation of systemic oxygen delivery in the treatment of critically ill patients. N Engl J Med. 1994;330:1717-22.

65. Wilkman E, Kaukonen KM, Pettilä V, Kuitunen A, Varpula M. Association between inotrope treatment and 90-day mortality in patients with septic shock. Acta Anaesthesiol Scand. 2013;57: 431-42.

66. Rhodes A, Lamb FJ, Malagon I, Newman PJ, Grounds RM, Bennett ED. A prospective study of the use of a dobutamine stress test to identify outcome in patients with sepsis, severe sepsis, or septic shock. Crit Care Med. 1999;27:2361-6.

67. Kumar A, Schupp E, Bunnell E, Ali A, Milcarek B, Parrillo JE. Cardiovascular response to dobutamine stress predicts outcome in severe sepsis and septic shock. Crit Care. 2008;12:R35.

68. Lyte M, Freestone PPE, Neal CP, Olson BA, Haigh RD, Bayston R, et al. Stimulation of Staphylococcus epidermidis growth and biofilm formation by catecholamine inotropes. Lancet. 2003;361:130 5.

69. Hartemink KJ, Groeneveld ABJ. Vasopressors and inotropes in the treatment of human septic shock: effect on innate immunity? Inflammation. 2012;35:206-13.

70. Barton P, Garcia J, Kouatli A, Kitchen L, Zorka A, Lindsay C, et al. Hemodynamic effects of i.v. milrinone lactate in pediatric patients with septic shock. A prospective, double-blinded, randomized, placebo-controlled, interventional study. Chest. 1996;109:1302-12.

71. Schmittinger CA, Dünser MW, Haller M, Ulmer H, Luckner G, Torgersen $\mathrm{C}$, et al. Combined milrinone and enteral metoprolol therapy in patients with septic myocardial depression. Crit Care. 2008;12:R99.

72. Morelli A, De Castro S, Teboul J-L, Singer M, Rocco M, Conti G, et al. Effects of levosimendan on systemic and regional hemodynamics in septic myocardial depression. Intensive Care Med. 2005;31:638-44.

73. Zangrillo A, Putzu A, Monaco F, Oriani A, Frau G, De Luca M, et al. Levosimendan reduces mortality in patients with severe sepsis and septic shock: a meta-analysis of randomized trials. J Crit Care. 2015;30:908-13.

74. Gordon AC, Perkins GD, Singer M, McAuley DF, Orme RML, Santhakumaran S, et al. Levosimendan for the prevention of acute organ dysfunction in sepsis. N Engl J Med. 2016;375:1638-48. LeoPARDS Trial.

75. Suzuki T, Morisaki H, Serita R, Yamamoto M, Kotake Y, Ishizaka A, et al. Infusion of the beta-adrenergic blocker esmolol attenuates myocardial dysfunction in septic rats. Crit Care Med. 2005;33: 2294-301.

76. de Montmollin E, Aboab J, Mansart A, Annane D. Bench-tobedside review: Beta-adrenergic modulation in sepsis. Crit Care. 2009;13:230.

77. Macchia A, Romero M, Comignani PD, Mariani J, D'Ettorre A, Prini N, et al. Previous prescription of $\beta$-blockers is associated with reduced mortality among patients hospitalized in intensive care units for sepsis. Crit Care Med. 2012;40:2768-72.

78. Morelli A, Ertmer C, Westphal M, Rehberg S, Kampmeier T, Ligges S, et al. Effect of heart rate control with esmolol on hemodynamic and clinical outcomes in patients with septic shock: a randomized clinical trial. JAMA. 2013;310:1683-91. Esmolol Trial.

79. De Santis V, Frati G, Greco E, Tritapepe L. Ivabradine: a preliminary observation for a new terapeutic role in patients with multiple organ dysfunction syndrome. Clin Res Cardiol. 2014;103:831-4.

80. Nuding S, Schröder J, Presek P, Wienke A, Müller-Werdan U, Ebelt $\mathrm{H}$, et al. Reducing elevated heart rates in patients with multiple organ dysfunction syndrome with the If (funny channel current) inhibitor ivabradine. Shock. 2017;49(4):402-11. MODiFy Trial.

81. Lo JCY, Darracq MA, Clark RF. A review of methylene blue treatment for cardiovascular collapse. J Emerg Med. 2014;46:670-9.

82. Kirov MY, Evgenov OV, Evgenov NV, Egorina EM, Sovershaev MA, Sveinbjørnsson B, et al. Infusion of methylene blue in human septic shock: a pilot, randomized, controlled study. Crit Care Med. 2001;29:1860-7. 
83. Memis D, Karamanlioglu B, Yuksel M, Gemlik I, Pamukcu Z. The influence of methylene blue infusion on cytokine levels during severe sepsis. Anaesth Intensive Care. 2002;30:755-62.

84. Schlesinger JJ, Burger CF. Methylene blue for acute septic cardiomyopathy in a burned patient. J Burn Care Res. 2015;37(3):e28791.

85. Zhou Q, Pan X, Wang L, Wang X, Xiong D. The protective role of neuregulin-1: a potential therapy for sepsis-induced cardiomyopathy. Eur J Pharmacol. 2016;788:234-40.

86. Fisher BJ, Kraskauskas D, Martin EJ, Farkas D, Puri P, Massey HD, et al. Attenuation of sepsis-induced organ injury in mice by vitamin C. JPEN J Parenter Enteral Nutr. 2014;38:825-39.

87. Yang L, Zhang H, Chen P. Sulfur dioxide attenuates sepsis-induced cardiac dysfunction via inhibition of NLRP3 inflammasome activation in rats. Nitric Oxide. 2018;81:11-20.

88. Pertzov B, Eliakim-Raz N, Atamna H, Trestioreanu AZ, Yahav D, Leibovici L. Hydroxymethylglutaryl-CoA reductase inhibitors (statins) for the treatment of sepsis in adults - a systematic review and meta-analysis. Clin Microbiol Infect. 2019;25:280-9.

89. Wang Y, Zhang L, Zhao X, Yang W, Zhang R. An experimental study of the protective effect of simvastatin on sepsis-induced myocardial depression in rats. Biomed Pharmacother. 2017;94:705-11.

90. Kong W, Kang K, Gao Y, Liu H, Meng X, Yang S, et al. Dexmedetomidine alleviates LPS-induced septic cardiomyopathy via the cholinergic anti-inflammatory pathway in mice. Am J Transl Res. 2017;9:5040-7.
91. Bagate F, Razazi K, Boissier F, Seemann A, de Prost N, Carteaux G, et al. Association between relative adrenal insufficiency and septic cardiomyopathy: a preliminary report. Intensive Care Med. 2017;43:1924-6.

92. Yu X, Wang Y, Yang D, Tang X, Li H, Lv X, et al. $\alpha 2$ A-adrenergic blockade attenuates septic cardiomyopathy by increasing cardiac norepinephrine concentration and inhibiting cardiac endothelial activation. Sci Rep. 2018;8:5478.

93. Wang Y, Yu X, Wang F, Wang Y, Wang Y, Li H, et al. Yohimbine promotes cardiac NE release and prevents LPS-induced cardiac dysfunction via blockade of presynaptic $\alpha 2 \mathrm{~A}$-adrenergic receptor. PLoS One. 2013;8:e63622.

94. Zhang X, Dong S, Qin Y, Bian X. Protective effect of erythropoietin against myocardial injury in rats with sepsis and its underlying mechanisms. Mol Med Rep. 2015;11:3317-29.

95. Zabet MH, Mohammadi M, Ramezani M, Khalili H. Effect of highdose ascorbic acid on vasopressor's requirement in septic shock. J Res Pharm Pract. 2016;5:94-100.

96. Fowler AA, Truwit JD, Hite RD, Morris PE, DeWilde C, Priday A, Fisher B, et al. Effect of vitamin $\mathrm{C}$ infusion on organ failure and biomarkers of inflammation and vascular injury in patients with sepsis and severe acute respiratory failure: the CITRIS-ALI randomized clinical trial. J Am Med Assoc. 2019;322(13):1261-70.

Publisher's Note Springer Nature remains neutral with regard to jurisdictional claims in published maps and institutional affiliations. 